\title{
Werner Stelzner*
}

\section{COMPATIBILITY AND RELEVANCE: Bolzano and Orlov}

\section{Orlov's basic ideas on his way to relevance: compatibility and containment}

For a dozen years the Russian engineer and logician I. E. Orlov (1886 - not before 1936$)^{1}$ has been recognized as the founder of the first precisely elaborated modern system of relevance logic. ${ }^{2}$ On his way to this result around the middle of 1920s, Orlov underwent a deep and astonishing change in his philosophical position and his attitude towards logic. While his work until 1925 is replete with declarations of the superiority of (Marxist-Leninist) dialectics to formal logic, his epoch-making Calculus of the compatibility of sentences shows a surprising departure from the ideological orientation of the earlier papers. It is a serious contribution to the development of modern non-classical logics, in an up-to-date technical presentation. ${ }^{3}$

In this paper of 1928 Orlov not only presented his calculus of relevance logic, but also developed, two years before Oskar Becker and five years before

* The author is grateful to the German Research Foundation (Deutsche Forschungsgemeinschaft) and the University of Bremen for their invaluable support, which made it possible to realize this research. Special thank to Rolf George for his giant help in preparing the Englisch text of this paper.

${ }^{1}$ With these dates I follow information from Bazhanov's impressive report about the personal life of Orlov (cf. Bazhanov 2001).

${ }^{2}$ Došen 1990, 2; Anderson/Belnap/Dunn 1992, xvii.

3 These changes were accompanied by a shift to a different journal, from Under the banner [colours] of Marxism to Mathematical collection. 
Gödel's pioneering paper (though perhaps not with the latter's technical finesse), the modal-logical interpretation of intuitionistic logic in the modal part of system S4. He did, however, base intuitionistic logic not on classical, but on a relevance logic. In 1933 Gödel was convinced that Becker had developed S4, and even today most logicians dealing with the subject share this conviction.

For more than half a century the achievements of Orlov went unnoticed not only by Gödel, but also by later logicians and historians of logic. The first detailed presentation of Orlov's 1928 paper is Dosen's 1990 report, though Popov's Russian paper from 1978 should be mentioned as well. Following these papers the preface of Anderson/Belnap/Dunn (1992), corrects the very important earlier claim concerning the history of relevance logic from volume I (1975):

In that volume we passed on our belief that the earliest versions of relevance logic were those of Moh 1950 and Church 1951. [...] We certainly missed the truth by over two decades: relevance logic was already treated with insight and rigor by Orlov 1928.

[Anderson/Belnap/Dunn 1992, xvii]

Only three years before his astonishing paper from 1928 Orlov had published Logical calculus and traditional logic [Orlov 1925] and other papers in the most important philosophical journal of the early Soviet Union Under the Banner [colours] of Marxism. In this paper he agrees with an earlier piece by Bammel [Bammel 1925], thus saving himself the trouble of formulating his own general objections to Logistics.

Com[rade]. Bammel has fundamentally developed in his paper what the so-called 'Logistic', which is given so much importance in idealistic thought, in reality represents. Because of this I can confine myself to shedding light on a partial question, namely, the relation of mathematical logic to traditional logic.

[Orlov 1925, 69]

Orlov maintained that the proponents of modern mathematical logic he refers in particular to Peano and Russell - behaved very condescendingly towards "Aristotelian" logic, asserting to have surmounted it, stating that their mathematical logic is something fundamentally new. It introduces, they maintain, entirely new principles of deriving conclusions, which specify and sharpen the old principles. According to Orlov, all this is false:

Although we have no objection to the possibility of developing logic in symbolic form, we don't find any principle in the logical calculus not 
given by a syllogism of the common type. By the way, the clearing of this circumstance has essential importance; the insufficiency of formal logic is so manifest for us, like the necessity of a completion of formal considerations by dialectical ones. From this it is evident that mathematical logistics is not a universal mathematical method.

[Orlov 1925, 69]

After mentioning these merely ideological-philosophical views, which were characteristic of the broader context in which Orlov's work was embedded, we now consider the main theoretical thrust of his papers preceding his Calculus of the Compatibility of Sentences of 1928.

There is strong evidence in his 1925 paper about the relation between traditional and modern mathematical logic that Orlov's main theoretical subject is already the search for "the basic relation of logical calculi, the relation of conclusion-connection (implication)" [Orlov 1925, 69; 1925c, 58]. In fact, already in the 1925 writings some starting points for relevant logical thinking came to the surface. In these papers Orlov developed the theoretical tool of Coexistence and used it to analyze and explicate relevant implicative connections. ${ }^{4}$ By "coexistence" Orlov doesn't understand a spatial or generally viewable (figurative) relation, but a logical relation between two objects, one of them given under the condition of the other: "p is given under the condition q". In Orlov's relevance-paper of 1928 these objects are specified as sentences.

In this context in 1925 Orlov discusses the problem of elements falling under a class, explaining this as a kind of partial identity: The singular term $K$ belongs to the class $a$, if this term is identical with some member of class $a$. [cf. Orlov (1925), 70, f.] Starting from these considerations, Orlov underlines the distinction between hypothetical judgments of traditional logic and categorical judgments, touching on a characteristic discussion inside the traditional logic of the $19_{\text {th }}$ century. ${ }^{5}$ In connection with this, he refers to the difference between the intensional and the extensional treatment of judgments:

It is well known, that the categorical judgments have a twofold sense: They can be considered according to the content of the terms, or according to their extension.

[Orlov 1925, 71]

\footnotetext{
${ }^{4}$ Remarks by Orlov about coexistence are already contained in a paper from 1923 (Orlov 1923).

${ }^{5}$ Cf. Herbart 1884 ff., Bolzano 1837, Lotze 1843, 1874, Sigwart 1873.
} 
Only in the first (intensional) case are categorical judgments reducible to hypothetical ones. Hypothetical judgments are related to the conceptual content of the connected judgments, and in this sense they are intensional judgments. ${ }^{6}$

In a somewhat strange and rather traditional way, Orlov defends the view that from two judgments about the belonging of an element to a class it is impossible to get a conclusion. Such judgments merely express partial identities, and from two partial identities nothing follows. These views, too, demonstrate his connection with traditional logic and traditional syllogistics. However, his aim is to bring into consideration intensional relations:

If a conclusion is to be drawn it is necessary to have the relation of belonging to a class connected with 'Implications', i.e., to combine partial identity with coexistence. And this is characteristic especially for categorical syllogisms. [Orlov 1925, 71]

Thus it is in traditional, rather than modern mathematical logic, that Orlov sees realized his aim of connecting extensional with intensional considerations. However, this is not the only point in which traditional logic is superior to modern mathematical logic. According to Orlov, another advantage is that traditional logic has a smaller number of basic laws and basic concepts than modern mathematical logic:

The logical calculus makes it its business to reduce the number of basic principles and basic concepts to the smallest possible number. But in this connection, traditional logic has a definite advantage. In fact, all conclusions of traditional logic can be reduced to the application of the formal laws of thought: the law of the identity and the law of contradiction. ${ }^{7}$ It may be mentioned in passing that in the logical calculus we find a whole string of principles that are entirely superfluous or at least derived.

[Orlov 1925, 71 f.]

As an example, Orlov chooses the substitution rule. He repeats Mill's account of general judgments and argues that the truth of a general judgment

\footnotetext{
${ }^{6}$ This opinion is shared by some traditional logicians, e.g., Sigwart in his work about hypothetical judgments $(1871,1873)$.

${ }^{7}$ In a footnote, however, Orlov adds: "For complete precision it is necessary to remember the law of excluded middle, which is not identical with the law of contradiction. What actually holds is this: from an assertion one can conclude the negation of the negation on the basis of the law of contradiction, but the negation of a negation entails the assertion only if the law of the excluded third is brought into play." [Orlov 1925, 71]. Apparently, Orlov already points to relations that are important for the treatment of intuitionistic logic in his paper of 1928.
} 
to which the substitution rule is applied presupposes the truth of all the singular judgments that are produced with the substitution rule.

After discussing more examples of logical principles stemming from the logic of relations, Orlov arrives at frankly negative assessment of the benefit and efficiency of the new logic and of formal methods in general:

And so we see that the authors of the works about the logical calculus cannot praise themselves for any principal advance over the "Logic of Aristotle". Their logic, in the final result, is only a modification of traditional logic. From this follows that logistics has the same shortcomings as traditional logic, which I pointed out repeatedly in the pages of Under the Banner of Marxism. The inferences have no ratiocinative merit, but are just ways of searching for new aspects of the meaning of the premisses; in the end all conclusions are drawn indirectly; the deduction does not deliver materially true judgments, but judgments following from their premisses; any formal conclusion contains a petitio principii etc.

All these shortcomings are integral aspects of the traditional logic, but also of the logistic calculus and generally of every formal method. This characterizes formal logic as less accomplished than dialectics, as a supporting method with only limited importance. [Orlov 1925, 74]

In view of these assertions, Orlov's development leading to the publication of Calculus of the Compatibility of Sentences in 1928 is more than surprising, almost unbelievable. In this paper, no doubt after extensive preparatory work, he presents surprising positive results within the very science he had characterized in his 1925 paper as wholly unable to produce anything important. One is almost inclined to believe in an accidental sameness of personal names, so huge is the gap and the contrast between the views published in 1925 and the results of 1928. Maybe this was itself a dialectical development.

Orlov starts his relevance-paper with the consideration that by excluding certain axioms of the propositional calculus one can obtain "the most general part of mathematical logic", a symbolic system that deviates essentially from the classical theory. With his idea of obtaining a new system of logic by excluding some axioms of a given system, Orlov used the same strategy as another Russian logician, N. A. Vasil'ev, had pursued almost twenty years earlier in his project of constructing a non-aristotelian logic. ${ }^{8}$ However, the actual projects of the two logicians differ profoundly, even if the starting idea and the results are in some sense similar.

\footnotetext{
${ }^{8}$ Vasil'ev 1910, 1912, 1912/13, 1925.
} 
Orlov formulates his main position concerning relevance in the following statement:

Classical logic is based on the well-known concept of material entailment, which can connect in one formula two sentences that have no inner connection according to their sense. By contrast, the system we have in mind will be able to handle in symbolic form the sense-relations between sentences. In connection with this the system does not consider in the first place the question of the truth or falsehood of given sentences, but the question of the compatibility among them.

[Orlov 1928, 263]

His remark not to consider in the first place the question of truth and falsehood, is still in keeping with Orlov's 1925 attitude towards formal logic. But the alleged disadvantage of formal (and mathematical) logic of not leading to materially true sentences (in contrast to dialectics), becomes, relevantly reversed, the starting point for positive theory-development in 1928. According to Orlov, now not truth or falsehood, but the compatibility of sentences should be crucial for logical entailment.

In Bernard Bolzano Orlov had a great predecessor in the attempt of deriving the concept of logical consequence, and indeed of relevant consequence, from the concept of compatibility of sentences. It is appropriate, therefore, to turn to Bolzano in order to check out parallels and divergences in the treatment and role of the compatibility of sentences in Bolzano's and Orlov's logical projects. A further point of interest is Bolzano's notion of Ableitbarkeit (deducibility), which comprises some elements of relevance and is not based on material implication in that an Ableitbarkeit of $B$ from $A_{1}$, $A_{2}, \ldots, A_{n}$ holds just in case a material conditional $A_{1} \wedge A_{2} \wedge \cdots \wedge A_{n} \supset B$ is logically valid.

\section{Compatibility and deducibility (Ableitbarkeit) in Bolzano's Wissenschaftslehre}

\subsection{Truth and sentences as such (Sätze an sich)}

Maintaining a firm anti-psychologistic attitude, Bolzano distinguishes sentences that are articulated in speech or thought from their content, namely objective sentences or sentences in themselves. These objective sentences need not be empirically realized and don't have to be in a material or psychological form (cf. [Bolzano 1837, §122, 66]). Sentences in themselves are objective in the manner of Fregean thoughts and they do not exist as physical or mental entities. 
Sentences in themselves also share the most important logical feature of Fregean thoughts, namely, to be true or false in the classical sense, i.e., true or false independently of space and time. "Sentences, in which nothing is changed, are not sometimes true and sometimes false; but they are only one of these for ever" [Bolzano 1837, §155, 183]. In this context, it is important to have in mind the difference between a sentence in itself and its expression in language [Bolzano 1837, §125, 69]. According to Bolzano, the standard forms for expressing sentences in themselves are

(1) A has b

(2) A has lack of b,

where 'A' stands for an arbitrary idea in itself and ' $b$ ' for an arbitrary property idea. [Bolzano, §127, §136] Hence every sentence in itself (affirmation or negation) in its standard form has a subject and a predicate. One of the most important features of Bolzano's treatment of sentences is the condition that a sentence is true only if its subject idea is not empty, i.e. if there is at least one object falling under that idea. Hence both (1) and its negation (2) can be false, if the subject ideas A is empty, does not refer to an object (lacks Gegenständlichkeit). It follows that one must distinguish the negation (2) from the denial (Verneinung) of (1), i.e. "It is false that A has b", because denial and negation are equivalent only if the subject idea is not empty.

\subsection{Variations of sentences}

Even if there can be no doubt about the validity of the bivalence concerning truth and falsehood of sentences in themselves, Bolzano mentions that the impression can arise that the same sentence could be true or false depending on the times, places and objects connected with it. But this appearance arises because not the same sentence is considered in different situations, but some notions in the sentence are construed as variable. By varying certain components of a given sentence other sentences are constructed, some of which might be true, others false [Bolzano 1837, §147]. But every sentence resulting from such a variation is in turn unchangeably classically true or false and not both or neither. So sets of variations can be built up from a given sentence by replacing certain of its components (simple or complex) that are chosen as variable parts, with other notions (simple or complex) [Bolzano 1837, §147, 136 and $\S 69, \S 108]$. A variation of a sentence then comes about by replacing each occurrence of certain of its component parts with the same (simple or complex) notion, while different variable parts require different substitutions. From the sentence "Socrates is a Greek and Socrates 
is mortal" the variation "Bush is a Greek and Bush is mortal" can be obtained by varying the notion "Socrates". By varying "Greek" and "mortal" we can get the variations "Socrates is a German and Socrates is married" and by varying "Socrates", "Greek" and "mortal" we get "Aristotle is immortal and Aristotle is unmarried".

What I have said so far could lead to the impression that variable notions (or variable "ideas", Vorstellungen in Bolzano's words) should be thought of as variables in a logical formula, to be replaced like variables in ordinary substitutions. Two points must be made here. First, there are no variables in sentences, only notions (simple or composed), which (if chosen to be variable notions) are replaced by other notions. Second, if replaced, they should be replaced in all occurrences, where it is not part of another variand, by the same notion and different variable notions should replace different variable notions. If no logical notions are replaced (Bolzano allows the replacement even of logical notions), then the logical structure of the sentence and all its variations is the same. So, the variations are not logical forms in the usual sense, from which we obtain the sentence by substitution, which allows different logical forms for the same sentence.

To facilitate the presentation and make it clearer, I shall use the following abbreviation:

$$
\begin{aligned}
& \operatorname{var}\left(A, B,\left\{i / i^{\prime}, j / j^{\prime}, \ldots\right\}\right) \text { for replacing the variable parts } i, j, \ldots \\
& \text { with } i^{\prime}, j^{\prime}, \ldots \text {. }
\end{aligned}
$$

The variable parts, following a suggestion of Rolf George, will be named "variands". The "variands $i, j, \ldots$ occur in $A$ " will be abbreviated by " $\mathrm{E}(A,\{i, j, \ldots\})$ ". In addition we use the abbreviations " $\mathrm{T}(A)$ " for " $A$ is true" and " $\mathrm{F}(A)$ " for " $A$ is not true" (or in other words " $A$ is false"). As signs

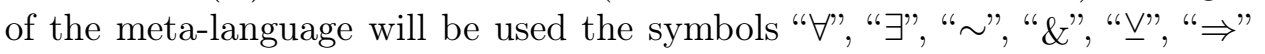
and " $\Leftrightarrow$ ".

By definition we introduce "Sentence $B$ is a variation of $A$ with respect to the variands $i, j, \ldots$ ":

$$
\operatorname{Var}(A, B,\{i, j, \ldots\}) \stackrel{\mathrm{df}}{=} \exists i^{\prime} \exists j^{\prime} \ldots \operatorname{var}\left(A, B,\left\{i / i^{\prime}, j / j^{\prime}, \ldots\right\}\right) .
$$

\subsection{Validity}

Bolzano introduces the notion of the degree of validity (or, in more modern terms, satisfiability) of a sentence based on the variation-method:

How much a sentence is valid or how much validity it has, should mean the same, as the proportion between the number of true sentences that 
are generated from this sentence if certain ideas in the original sentence are considered variable and replaced by others, compared with the number of all sentences generated this way. [Bolzano, §147, $138 \mathrm{f}$.]

To determine this relation, the notions substituted for the variands $i, j$, ... may not be extensionally equivalent (not gleichgeltend) and must be chosen to generate only referring (i.e., a non-empty gegenständliche) sentences [Bolzano, § 147, 138].

Furthermore, certain sortal specifications must be brought into play. If $k$ is the name of a person occurring in some sentence, and is chosen as a variand, then only notions referring to individual humans may be substituted for it. If this is presupposed, a universally or fully satisfiable sentence, or sentence true by virtue of its kind or form (allgemein or durchaus gültiger Satz, seiner ganzen Art oder Form nach wahrer Satz) with respect to variands $i, j, \ldots$ is defined as a sentence with only true variations resulting from substitutions on $i, j, \ldots$.

(DB2)

$$
\operatorname{ag}(A,\{i, j, \ldots\}) \stackrel{\mathrm{df}}{=} \forall B(\operatorname{Var}(A, B,\{i, j, \ldots\}) \& \mathrm{E}(A,\{i, j, \ldots\}) \Rightarrow \mathrm{T}(B))
$$

Correspondingly I define what it is for a sentence to be universally unsatisfiable or false by virtue of its kind or form

(DB3)

$$
\operatorname{ug}(A,\{i, j, \ldots\}) \stackrel{\mathrm{df}}{=} \forall B(\operatorname{Var}(A, B,\{i, j, \ldots\}) \& \mathrm{E}(A,\{i, j, \ldots\}) \Rightarrow \mathrm{F}(B))
$$

We have the following metatheorems:

$$
\operatorname{ag}(A,\{i, j, \ldots\}) \Longleftrightarrow \mathrm{ug}(\mathrm{Neg} . A,\{i, j, \ldots\}),
$$

where the negation Neg. $A$ says that $A$ is false

$$
\operatorname{ag}(A,\{i, j, \ldots\}) \& M \subseteq\{i, j, \ldots\} \& M \neq \emptyset \Longrightarrow \operatorname{ag}(A, M)
$$

\subsection{Compatibility}

\subsubsection{Variations and compatibility}

Bolzano considers various relations among sentences and sets of sentences. The most important of these is the compatibility of sentences, explained as a semantic relation. On the basis of this relation other crucial concepts of Bolzano's logic, among them deducibility (Ableitbarkeit) and consequence (Abfolge) are introduced. The semantic relations of compatibility and in- 
compatibility must be distinguished from certain syntactic relations of oppositeness, like those between sentences with opposite subjects or opposite predicates, or between a sentence and its negation. While the syntactic oppositions are absolute, the semantic compatibility or incompatibility is in every case related to sets of variable ideas.

These variable ideas need not be primitive, but may be composite. So, even on Bolzano's classical conception of truth, the sentences "A is B" and "A is non-B" are compatible with respect to the variand "non-B", or to the variands "non-B" and "B". In the last case the variable part "non-B", although composite, has to be taken a whole, so that substitutions for "B" and "non-B" can be carried out independently of each other. ${ }^{9}$

Technically, the introduction of the notion of compatibility is an application of Bolzano's variation method. Compatibility is introduced parameterrelativized in relation to such ideas, taken as variable parts in the sentences in question:

If we, however, compare several sentences $\mathrm{A}, \mathrm{B}, \mathrm{C}, \mathrm{D}, \ldots$, and consider as the variable ideas certain ideas $i, j, \ldots$, which conjointly occur in these sentences (maybe in every sentence one or the other): then arises the question, whether there are any ideas substituted for $\mathrm{i}, \mathrm{j}, \ldots$, which are of such a nature that those sentences by this substitution will be all true at the same time?

[Bolzano, § 154, $157 \mathrm{f.}]$

If this question has an affirmative answer, then the sentences $A, B, C, D$, ... are compatible with each other, otherwise incompatible. As an example Bolzano offers the sentences "This flower is red", "This flower has a pleasant fragrance", and "This flower belongs to the twelfth class of Linne's system", which are compatible with respect to the variable idea "this flower", because all three sentences will be true if we substitute for the variand "this flower" the idea "rose".

Symbolizing the expression "The sentences $A, B, \ldots$ are compatible with respect to the ideas $i, j, \ldots$ " by "com $(A, B, \ldots,\{i, j, \ldots\})$ ", we can define:

$$
\begin{gathered}
\operatorname{com}(A, B, \ldots,\{i, j, \ldots\}) \stackrel{\mathrm{df}}{=} \exists i^{\prime} j^{\prime} \ldots\left(\operatorname{Var}\left(A, A^{\prime},\left\{i / i^{\prime}, j / j^{\prime}, \ldots\right\}\right) \&\right. \\
\left.\operatorname{Var}\left(B, B^{\prime},\left\{i / i^{\prime}, j / j^{\prime}, \ldots\right\}\right) \& \cdots \& \mathrm{~T}\left(A^{\prime}\right) \& \mathrm{~T}\left(B^{\prime}\right) \& \cdots\right) .
\end{gathered}
$$

The following meta-theorem shows that compatibility is immune against enlargements of the set of variands:

$$
\operatorname{com}(A, B, \ldots,\{i, j, \ldots\}) \Longrightarrow \operatorname{com}(A, B, \ldots,\{i, j, \ldots\} \cup\{l, m, \ldots\})
$$

\footnotetext{
${ }^{9}$ Cf. George 1986.
} 


\subsubsection{Compatibility and consistency}

Given the way Bolzano introduced the notion of compatibility, it depends upon the concepts chosen as variands, whether or not sentences are compatible. Every sentence has true as well as false variations if there are no restrictions on the choice of variands. Analogously, for any collection of sentences there is some choice of variands with respect to which they are compatible:

If we are permitted to increase without limitation the number of concepts chosen as variands in a given collection of sentences, then these sentences will always appear compatible.

[Bolzano, §154, 159]

It holds in particular that all sentences with variable predicate are compatible [Bolzano, §154, 159]. From this it follows immediately that even syntactically opposite sentences like "A is b" and "A is non-b" can be compatible with each other, namely, if "non-b" is taken as variand. "Non-b" is varied independently of "b". Since, if this were not be the case, sentences with contradictory predicates would not be compatible. ${ }^{10}$ As well, this underlines the necessity of fixing the variands of a collection of sentences. If variands are not determined, calling a collection of sentences compatible is to say nothing special about them.

This treatment of variations, advanced e.g. by George, was disputed within the Bolzano-Community, especially by Jan Berg. He held that even if Bolzano allowed as variands not only primitive but also compound concepts, the independent variation of the parts $A$ and non- $A$ inside one sentence should nonetheless be prohibited. ${ }^{11}$ Berg's aim is to secure the compositional structure of his explication of Bolzano's formalized language. In Bolzano such a restriction on variands cannot be found. However, such a restriction would not contradict Bolzano's explicit statements about the compatibility of any

\footnotetext{
${ }^{10}$ Cf. George 1986.

11 "In addition to simple ideas in themselves, combinations of ideas in themselves can be varied. However, in this case all complex ideas occurring in a sentence have to be varied in the same way. For instance, in a sentence in itself of the form $A$ and non $A$ the two complex ideas $A$ and non $A$ cannot be varied independently of each other. Because of this, views like those in George (4) and (6), $\S 6$, are impossible in Bolzano's variation logic." (Berg 1987, 17). Berg's introduction of a general notion of compatibility in Bolzano in D10 on p. 20 (Berg 1987) seems to stem from an addiction to modern logical terminology. He says that a collection of sentences is compatible, if there is some set of variands relative to which this collection is compatible. In this sense every such collection is compatible and the notion is useless and there is not point in introducing it, as Bolzano himself (not Berg) points out. (See: Bolzano, § 164, 25).
} 
collection of sentences, if arbitrary variands can be chosen. Even if, contrary to Bolzano's stipulations, the variation of complexes were not allowed, one can take (primitive) logical concepts as variands, and in many cases obtain the same effect on compatibility (and consequently for deducibility (Ableitbarkeit) in Bolzano's treatment) as with complex variands. E.g., it holds $A \wedge$ $\sim A \vDash_{\{\sim\}} \sim A$, but not $A \wedge \sim A \vDash_{\{\sim\}} B$. The difference between complex variands and elementary variands is analogous to the difference between functorvariables and function-expression-variables in modern logical systems. ${ }^{12}$

Logically inconsistent sentences are compatible only with respect to variands whose variation changes the logical structure of these sentences, though, obviously, not every variation of logical structure makes a given set of sentences compatible. On the other hand there are sentences, which even are sound according to their form, if related to certain variations. ${ }^{13}$

Functor variables must be distinguished from function variables also in the case of Bolzano's Ableitbarkeit by choosing the whole functional expression as variand, as suggested by George. To illustrate the distinction, consider the following example: With the functor $\sim$ as variand we obtain $\operatorname{com}(A \wedge \sim A, B \wedge \sim B,\{A, B, \sim\})$, but not $\operatorname{com}(A \wedge \sim A, B \wedge \sim B,\{A, B, \sim A\})$ nor $\operatorname{com}(A \wedge \sim A, B \wedge \sim B,\{A, B, \sim B\})$, since in the last cases not all occurrences of the negation sign occur in variable parts.

\subsection{Deducibility}

\subsubsection{Deducibility and Variation}

On the basis of his variation method, Bolzano introduces a notion of deducibility [Ableitbarkeit], a semantic entailment-relation between sentences or collections of sentences:

$\mathrm{N}$ is called deducible [ableitbar] or following from [folgend aus] $\mathrm{M}$, if all ideas substituted for certain others taken as variands in these sentences which make the sentence $\mathrm{M}$ true, also make the sentence $\mathrm{N}$ true.

$[\S 154,167]$

This explication determines merely the framework for Bolzano's deducibility-relation, but does not completely define it. In order to give such a complete definition Bolzano adds a special compatibility condition for the pre-

\footnotetext{
12 Cf. Stelzner 1980.

${ }^{13}$ In systems with functor variables and systems with function variables such sentence forms find a logical treatment (cf. Leśniewski 1929, Łukasiewicz 1970, Stelzner 1980, Max 1988).
} 
misses and conclusions of a deduction, so that a deducibility-relation must satisfy two conditions:

\section{Positive compatibility-condition:}

For the relation of deducibility with respect to the variands $i, j, \ldots$ holds between the sentences $A, B, C, D, \ldots$ and the sentences $M, N, O, \ldots$, all sentences of these two sets must be compatible with respect to $i, j, \ldots$.

\section{Entailment-condition:}

If the compatibility-condition is satisfied, then "the sentences $M, N, O, \ldots$ are deducible [ableitbar] from the sentences $A, B, C, D, \ldots$ with respect to the variable parts $i, j, \ldots$, if every collection of ideas whose substitution for $i, j, \ldots$ makes all of $A, B, C, D, \ldots$ true also makes all of $M, N, O, \ldots$ true" [Bolzano, $\S 155,170]$.

Bolzano thus defines a multi-conclusion entailment, where every member of the conclusion set is entailed by the premisses: $A_{1}, \ldots, A_{n} \vDash_{v} B_{1}, \ldots, B_{m}$ iff $A_{1}, \ldots, A_{n} \vDash_{v} B_{1}$ and $\ldots$ and $A_{1}, \ldots, A_{n} \vDash_{v} B_{m}$.

\section{Definition of Bolzano-Ableitbarkeit:}

In the sequel I abbreviate: "The sentences $M, N, O, \ldots$ are deducible from the sentences $A, B, C, D, \ldots$ with respect to the variands $i, j, \ldots$ " as

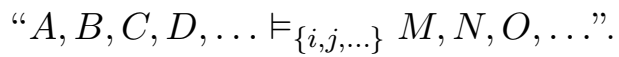

The (positive) compatibility-condition and the entailment-condition are united in the following definition of Bolzano-Ableitbarkeit: ${ }^{14}$

$$
\begin{aligned}
& A \vDash_{\{i, j, \ldots\}} B \stackrel{\mathrm{df}}{=} \operatorname{com}(A, B,\{i, j, \ldots\}) \& \forall i^{\prime} \forall j^{\prime} \ldots \\
& \left(\operatorname{var}\left(A, A^{\prime},\left\{i / i^{\prime}, j / j^{\prime}, \ldots\right\}\right) \& \operatorname{var}\left(B, B^{\prime},\left\{i / i^{\prime}, j / j^{\prime}, \ldots\right\}\right)\right. \\
& \left.\left(\mathrm{T}\left(A^{\prime}\right) \Rightarrow \mathrm{T}\left(B^{\prime}\right)\right)\right)
\end{aligned}
$$

\section{Negative compatibility-condition:}

Bolzano's notion of deducibility could also have been introduced without explicitly stating the entailment-condition. He could have introduced, instead, the following negative compatibility condition which envisages the (possible) falsehood of the conclusions:

If the positive compatibility-condition is fulfilled, then the sentences $M, N, O, \ldots$ are deducible from the sentences $A, B, C$, $D, \ldots$ with respect to the variands $i, j, \ldots$ iff the premises $A, B$,

\footnotetext{
14 The quantification used in the following considerations is a substitutional quantification over concepts (termini with sense).
} 
$C, D, \ldots$ are incompatible with the falsehood of any conclusion (i.e., incompatible with $\mathrm{F}(M), \mathrm{F}(N), \mathrm{F}(O), \ldots$ ) with respect to the variands $i, j, \ldots$

The mutual dependence between entailment-condition and negative compatibility condition (supposing the positive compatibility condition is fulfilled) is expressed by the following meta-theorem:

$$
\begin{aligned}
& A, B, C, D, \ldots \vDash_{\{i, j, \ldots\}} M, N, O, \ldots \Longleftrightarrow \Longleftrightarrow \\
& \operatorname{com}(A, B, C, D, \ldots, M, N, O, \ldots,\{i, j, \ldots\}) \& \\
& \sim \operatorname{com}(A, B, C, D, \ldots, \mathrm{F}(M),\{i, j, \ldots\}) \& \\
& \sim \operatorname{com}(A, B, C, D, \ldots, \mathrm{F}(N),\{i, j, \ldots\}) \& \\
&\sim \operatorname{com}(A, B, C, D, \ldots, \mathrm{F}(O),\{i, j, \ldots\}) \& \ldots) .
\end{aligned}
$$

If it is permitted to choose arbitrary concepts as variands, then every collection of sentences is compatible with respect to some set of variands. This is not the case with deducibility. It is not possible by freely choosing sets of variands to introduce a deducibility relation between any two collections of sentences.

In contrast to the case of compatibility, it is sometimes useful, in addition to the notion of deducibility relativized to variands, to introduce an absolute assertion that $B$ follows from $A$ (without mentioning a fitting set of variands). " $B$ is deducible from $A$ " in the sense that there are some variable parts in $A$, $B$ with respect to which $B$ follows from $A$ is not a trivial assertion. According to Bolzano, such a relation is worth considering, whereas he finds no use for the notion of absolute compatibility. ${ }^{15}$

\subsubsection{Deducibility and relevance}

2.5.2.1. Deducibility and transitivity. Due to the compatibility condition, Bolzano's deducibility is non-monotonic: By adding premisses it is possible to change a case of valid deducibility into an invalid one, if the extended set of premisses is not compatible with the conclusions or if the extended set is not itself compatible with respect to the chosen variands. Similarly, again due to the compatibility condition, the cut theorem doesn't hold for Bolzano's deducibility: We don't have $A \vDash_{v} B \& B, C \vDash_{v} D \Longrightarrow A, C \vDash_{v} D$. Here again, from $\operatorname{com}(A, B, v)$ and $\operatorname{com}(B, C, D, v)$ it does not follow that $\operatorname{com}(A, C, D, v) \cdot{ }^{16}$ If, however, all the sets of premisses under consideration

15 Bolzano, § 164, 26 f., see also: Kambartel 1978, XLI; Siebel 1996, 95 ff.

${ }^{16}$ Cf. Siebel 1996, 147. 
are compatible with their conclusions, then both, monotony and the cuttheorem hold.

Nevertheless, Bolzano's deducibility-relation is transitive without limitation. We have the following meta-theorem:

$$
M_{1} \vDash_{v} M_{1} \& M_{2} \vDash_{v} M_{3} \Longrightarrow M_{1} \vDash_{v} M_{3} .
$$

Consequently, Bolzano deducibility fulfills an important necessary condition, according to Anderson/Belnap that any entailment relation must satisfy: "Any criterion, according to which entailment is not transitive, is ipso facto wrong." 17 Anderson/Belnap directed their remark against the Smileycriterion for relevance, which states, "that $A_{1} \& \cdots \& A_{n}$ (relevantly) entails $B$ just in case that $\left(A_{1} \& \cdots \& A_{n} \supset B\right.$ is a substitution instance of a tautology $\left(A_{1}^{\prime} \& \cdots \& A_{n}^{\prime}\right) \supset B^{\prime}$, such that neither $B^{\prime}$ nor the denial of $A_{1}^{\prime} \& \cdots \& A_{n}^{\prime}$ is provable" 18 . There are two main points of similarity between Bolzano deducibility and Smiley-entailment [Smiley 1959]. First Bolzano's compatibility condition for the premisses is like Smiley's for the antecedent of the formula from which the entailment is derived by substitution. So, in Smiley the entailment can have incompatible premisses, while its validity is based on the validity of a formula with compatible premisses. Bolzano deducibility cannot have premisses incompatible with respect to the variands of the deduction, but it can have premisses incompatible relative to another set of variands. Both, Bolzano and Smiley base their deducibility (or entailment) on a logical structure with compatible premisses. However, in Bolzano's case the transitivity of this relation is attained, while in Smiley transitivity breaks down. To illustrate with an example:

Formula (1) and (2) fulfill the Smiley criterion:

(1) $\quad(B \wedge \sim B) \rightarrow A \vee(B \wedge \sim B)$

(2) $\quad A \vee(B \wedge \sim B) \rightarrow A$

From (1) and (2) by transitivity:

(3) $\quad(B \wedge \sim B) \rightarrow A$.

\footnotetext{
${ }^{17}$ Anderson/Belnap 1975, 154. It deserves to be mentioned that the absolute deducibility relation introduced by Bolzano is not transitive.

18 Anderson/Belnap 1975, 153. At this place we will discuss only the compatibility conditions in Smiley and Bolzano. An analogous condition like Smiley's demand that the conclusion should be a substitution from a formula with a non-tautological conclusion amounts to strengthening the Bolzano deducibility in order not to allow tautological conclusions. For the strengthened Bolzano deducibility (which will be discussed later) a similar result like for the compatibility condition can be received.
} 
However, (3) does not fulfill the Smiley criterion. Accordingly, transitivity breaks down. The crucial point is that in Smiley (1) and (3) are treated differently, while in Bolzano they are treated in the same way: whatever sets of variands are chosen, (1) and (3) are both valid or both invalid.

2.5.2.2. Positive compatibility-condition and relevance. Because of the positive compatibility condition, Ableitbarkeit fulfills certain relevance conditions that would not arise from the entailment condition alone, which behaves merely like the classical entailment: ${ }^{19}$

1. True premisses that do not contain the variands $i, j, \ldots$ of the deduction, are irrelevant to the validity of the deduction.

2. A deduction that does not contain analytically true conclusions is valid only if at least some variands contained in the premisses are contained in the conclusions as well (variand-sharing-condition). Consequently it is impossible to deduce, with respect to the variands $i, j, \ldots$, a non-analytic sentence that does not contain at least one of the variable parts $i, j, \ldots$.

3. No sentence is deducible with respect to the variands $i, j, \ldots$ from a set of premisses containing a false sentence, if this sentence does not contain at least one of the variands $i, j, \ldots$, because such a false sentence would be incompatible with the other sentences of the deduction with respect to the variands $i, j, \ldots$ :

$$
A, B, C, D, \ldots \vDash_{\{i, j, \ldots\}} M, N, O, \ldots \& \sim \exists l \in\{i, j, \ldots\} \mathrm{E}(A,\{l\}) \Longrightarrow \mathrm{T}(A) .
$$

4. With respect to every set of variands, the negation of a sentence is never deducible from this sentence:

$$
\begin{aligned}
& \sim\left(A \vDash_{v} \text { Neg. } A\right), \\
& \sim\left(A \vDash_{v} \sim A\right) .
\end{aligned}
$$

So, Bolzano's deducibility relation fulfills an important relevance condition of connex conceptions of logical entailment. Bolzano explains this with the impossibility that a collection of concepts, which makes a sentence $A$ true, at the same time makes the sentence " $A$ is false" true.

5. Another connex relevance condition is fulfilled as well: From any sentence $A$ (or any collection of sentences) it is impossible to deduce both a

\footnotetext{
19 Some commentators, e.g. Scholz (1953, 12), Buhl (1961, 20), Berg (1981, 419), are interested in establishing Bolzano as the founder of the classical entailment relation. It is characteristic for these attempts at explaining the logical content of Bolzano's deducibility that the importance of the positive compatibility condition is neglected.
} 
sentence $B$ and its negation $\sim B$ with respect to variands $v$ :

$$
\begin{gathered}
\sim\left(A \vDash_{v} B \& A \vDash_{v} \sim B\right), \\
A \vDash_{v} B \Longrightarrow \sim\left(A \vDash_{v} \sim B\right) .
\end{gathered}
$$

6. If a sentence is not true because of its form relative to the variands $i$, $j, \ldots,{ }^{20}$ then this sentence is not deducible from both $A$ and $\sim A$ :

$$
\begin{gathered}
\sim\left(A \vDash_{v} B \& \sim A \vDash_{v} B\right), \\
A \vDash_{v} B \Longrightarrow \sim\left(\sim A \vDash_{v} B\right) .
\end{gathered}
$$

However, sometimes it is possible to infer the same conclusion from certain premisses and from the negation of all these premisses. An example for this is Bolzano's deduction of $\sim \forall x(B(x) \equiv C(x))$ from the premisses $\forall x(A(x) \supset B(x))$ and $\sim \forall x(A(x) \supset C(x))$, where the conclusion is also deducible from the negations of these same premisses. ${ }^{21}$

None of the meta-theorems concerning the relevance of Bolzano's deducibility mentioned so far hold for the classical entailment-relation. However, if we restrict the classical entailment-relation by prohibiting inferences from contradictions, then these meta-theorems hold analogously for the restricted classical entailment as well. This points to one of the reasons for non-relevance in classical logic, namely the classical treatment of contradictions. Nevertheless, Bolzano's deducibility does not coincide with restricted classical entailment, for, even if it is not possible to deduce from incompatible premisses, it is possible to deduce from contradictions, provided compatible variands are chosen. Thus in Bolzano's deducibility the following formulas are valid:

$$
\begin{gathered}
A, \sim A \vDash_{\sim A}(A \vee B) \wedge(\sim A \vee B), \\
A \wedge \sim A \vDash_{\sim A} A .
\end{gathered}
$$

But we don't have the irrelevant entailment (1) $A \wedge \sim A \vDash_{\sim A} B$ as a valid Bolzano-entailment. In fact, the validity of (TB12) and (TB13) is not connected with the classical feature that from a contradiction anything follows, but has its basis in the facts that every sentence follows from itself and that each conjunct follows from a conjunction. ${ }^{22}$

We now have to face the general problem of identifying the logical form of an argument (not of a formula in a logical calculus) and of evaluating an

\footnotetext{
${ }^{20}$ Cf. Bolzano, § 147.

${ }^{21}$ Cf. Bolzano, § 155, 173.

22 See George 1986.
} 
argument as logically correct or incorrect. ${ }^{23}$ As Gerald Massey has shown in a convincing way, in the usual treatment (not confined to classical logic), it is not true that arguments of invalid logical form are logically invalid. ${ }^{24}$ Sometimes arguments are claimed to be invalid because they instantiate some invalid form, when they instantiate as well a valid form, and are therefore valid. As George (paraphrasing Massey) pointed out:

Since this sort of thing sometimes occurs, one is never justified in judging an argument fallacious just because it is an instance of an invalid form, particularly given the apparently unfinished state of logic.

[George 1986, 559]

The problem here is not connected with different treatments of logical connectives in the diverse developments of logic. It is, rather, the problem that in the usual treatment a given argument has several logical forms, and there may even be forms not yet discovered.

In Bolzano's treatment the problem of the ambiguity of logical form does not occur. The evaluation of the logical correctness of an argument is impossible, if the variable parts of this argument are not determined. If this is done then, according to the definition of Ableitbarkeit, it is unambiguously determined whether or not the argument is valid. In Bolzano's treatment the presentation of an argument includes the specification of its logical form by the specification of its variable parts.

There are meta-theorems of classical shape that hold in Bolzano's entailment provided variands containing logical concepts (like $\sim \mathrm{A}$ ) are not allowed as variands. Two of the most important of these meta-theorems are contraposition and constructive dilemma [Bolzano, $\S 155,174]$ :

$$
\begin{aligned}
A, B, C, D, \ldots \vDash_{v} M \& \operatorname{com}(\sim M, B, C, D, \ldots, v) \Longrightarrow & \\
& \sim M, B, C, D, \ldots \vDash_{v} \sim A,
\end{aligned}
$$

if neither $\sim M$ nor $\sim A$ are chosen as variands.

If negation is subject to variation, then, nevertheless, a version of (TB14) holds, where $\sim M$ and $\sim A$ are replaced by $\mathrm{F}(M)$ and $\mathrm{F}(A)$ respectively.

Constructive dilemma holds without restriction:

$$
\begin{aligned}
& A, B, C, D, \ldots, X \vDash_{v} M, N, O, \ldots \& \\
& \quad A, B, C, D, \ldots, \sim X \vDash_{v} M, N, O, \ldots \Longrightarrow A, B, C, D, \ldots \vDash_{v} M .
\end{aligned}
$$

${ }^{23}$ Cf. George 1986, 559.

${ }^{24}$ Massey 1981, 499 ff. 
2.5.2.3. Precise relation of deducibility: Premiss relevance. Bolzano introduces as strengthened deducibility the relation of precise deducibility, which holds for a deducibility in case it is impossible to omit any of the premisses or a part contained in any of them, and have revised set of premisses still entail the given conclusion. ${ }^{25}$

It is a feature of precise deducibility that, given a set of variands, the negation of a conclusion is compatible with any proper subset of the premisses. As well, the negation of any premise must be compatible with all others and with the negations of all conclusions. It cannot be that that the negation of one premise is incompatible with the other premisses, because in this case it would be deducible from them. It could then be deleted from the premiss set, and the remaining premisses would still imply the given conclusion. Hence the deduction would not be precise. It is possible, however, that the negations of several premisses taken together are incompatible with the remaining premisses. This makes it possible to strengthen precise deducibility.

Bolzano develops here a premise-relevant relation of deducibility, with (1) only relevant premisses and (2) weakening of the premisses is considered in determining the relevance of the premisses for deducing the conclusion.

Precise deducibility, like deducibility in general, is relevant in the sense that deductions from incompatible premisses are disallowed. But it also rules out conclusions that are true by virtue of their form, because such sentences can be deduced from every compatible collection of sentences. It follows that precise deducibility with all premisses true by virtue of their form is impossible, since from such valid premisses only sentences true according to their form can be deduced.

By excluding the irrelevant entailment of conclusions true by virtue of their form, precise deducibility thus removes a weak point (in the context of relevance) of Bolzano's general deducibility. For the general deducibility it holds that every sentence true by virtue of its form (with respect to a set of variands) is deducible from every set of premisses compatible with respect to the same set of variands. Following a suggestion of George [George 1986], one can strengthen general deducibility in order to exclude those cases of irrelevancy. We can formulate an additional condition to be fulfilled by strengthened deducibility:

"The negation of any conclusion should be compatible with respect to the variands considered in the premisses and conclusions."

${ }^{25}$ Cf. Bolzano, § 155, 179. 
This does not mean, that a tautology can never be a conclusion. If we are not confined to logical deducibility, it is possible to deduce $A \vee \sim A$ from $A$ :

$$
\begin{gathered}
A \vDash_{\sim A} A \vee \sim A, \\
\sim A \vDash_{\sim A} A \vee \sim A .
\end{gathered}
$$

However, even with respect to the variand $\sim A$ we don't have the irrelevance $B \vDash_{\sim A} A \vee \sim A$. The strengthening sketched here does not prohibit all deductions of classically valid conclusions, only those that violate the relevancy condition.

Siebel has claimed that George's suggestion for strengthening deducibility would not be in the spirit of Bolzano. ${ }^{26}$ And in fact, Bolzano did not introduce the strengthening suggested by George. And so in the original Bolzano we have valid irrelevant deductions like $A \vDash_{v} B \vee \sim B$. In order forestall the dual irrelevance with incompatible premisses, Bolzano has to confine contraposition. George's suggestion just sketches a way to avoid both types of irrelevance, with the gain for Bolzano's deducibility that contraposition holds unrestrictedly. And that this is not against the spirit of Bolzano is shown by a variation of the deducibility-relation introduced by Bolzano himself, namely by his precise deducibility. Here Bolzano introduces a deducibility relation without incompatible premisses and without conclusions true by virtue of their form.

\section{Orlov's relevant logic}

\subsection{The intuitive foundation of Orlov's system}

Orlov constructs his system of relevant intuitionistic logic starting with the conviction that this system should overcome the main weakness of classical logic, whose entailment theory is founded in an generalization of the material implication, which can be true without any connection of sense between antecedent and consequent. Orlov advocates that his own system should be relevant in the sense that it can handle as a formalized system relations between the senses of antecedent and consequent. This is an aim Bolzano had undoubtedly reached as well with his theories of deducibility, even if he did not explicitly formulate it. As well, Bolzano's procedure seems to accord with Orlov's way to relevant logic. Not truth or falsehood, he said in the quote given above, but, as with Bolzano, the compatibility of sentences

\footnotetext{
${ }^{26}$ Siebel 1995, 246 ff.
} 
should be crucial for logical entailment. However, as we shall see, there are essential differences between the resulting logical theories, which derive at least partly from essential differences in the treatment of compatibility.

Orlov puts the elaboration of his new theory in the context of the "necessity of accommodating symbolic logic to the new procedures introduced by intuitionism" [Orlov 1928, 263]. Given Orlov's interest in intuitionism, his stress on the importance of compatibility is somewhat unexpected, since intuitionism focuses on an even stronger notion of truth than classical logic. Compatibility as a substitute for truth is a topic associated with Hilbertian formalism, not intuitionism. However, Orlov's treatment of intuitionism is not based on a new "intuitionistic" notion of truth, but depends on treating intuitionistic statements with the help of special additional epistemic operators. These in turn are based on the usual (not an intuitionistic) entailment system, which in Orlov's case is a relevant entailment system. Hence the most important special feature of intuitionism consists not in the introduction of a new notion of truth, but in the introduction of additional functions:

In the works of the intuitionists the defined notions don't depend directly on the [truth-values of the - W.S.] defining sentences $a, b, c, \ldots$, but on functions of these sentences, which are of the following kind: " ' $a$ is known as certain', ' $a$ is provable', ' $a$ can be reduced to absurdity', 'The absurdity of $a$ is absurd' etc."

[Orlov 1928, 263]

Orlov now appeals to the fact that in proving the law of excluded middle invalid, intuitionism comes into conflict with classical logic. He did not wish to revise this tenet of classical logic. In his view, one of the most important merits of his calculus of the compatibility of sentences is that within this calculus it is possible one can express the principles of intuitionism and yet retain the law of excluded middle.

To formulate the appropriate logical system, Orlov develops elements of a connex conception of logic that seems to be in full accordance with Bolzano's positive compatibility condition. Similar conceptions can be found in German traditional logic, e.g. in Christoph Sigwart's $\operatorname{logic}^{27}$ as well as in the Russian tradition in Vladislavlev's $\operatorname{logic}^{28}$, here however in a rather confused form. ${ }^{29}$ Orlov just states that conclusions may be drawn only if the premisses are compatible:

\footnotetext{
27 Sigwart 1871, 1873.

28 Vladislavlev 1872 and 1881.

29 See Stelzner 2001.
} 
For the possibility of a deductive conclusion the truth, generally speaking, is not necessary. ${ }^{30}$ It suffices that a weaker condition be fulfilled, viz. the compatibility of the premisses. From false premisses true conclusions may be deduced, but it is impossible to draw any conclusion at all from premisses that are not compatible with each other.

[Orlov 1928, 264]

After stressing the fundamental importance of compatibility Orlov surprisingly does not develop his system as a formalization of features of compatibility. In other words, he does not base his relevant implication and the corresponding entailment relation on a previously defined concept of compatibility, but goes the other way. He presupposes relevant implication $(A \rightarrow B$ : " $B$ follows from $A$ " or " $A$ implies $B$ ") and defines the compatibility of $A$ and $B$ ( $A$. B: " $A$ is compatible with $B$ ") simply as an abbreviation of " $A$ does not imply non- $B$ ".

Orlov thus postulates that sentence $a$ is compatible with sentence $b$ if, and only if, the negation of $b$ does not follow from $a$. This then is the essential difference between his and Bolzano's construction of his logical system. Bolzano starts with the introduction of compatibility, what it means for a sentence or a collection of sentences to be compatible with each other, which is independent of his notion of deducibility. As stated above, it was possible for Bolzano to define deducibility entirely in terms of compatibility and incompatibility. Orlov went in the opposite direction. While his notion of compatibility is an inferential one, and is not really required for the construction of his logical system, Bolzano's compatibility is a semantic fulfillment compatibility defined in terms of his variation method and indispensable for the construction of the system.

\subsection{Orlov's calculus of the compatibility of sentences}

As mentioned, the name Orlov chose was calculus of the compatibility of sentences, but this does not refer to a primitive, but to a secondary, concept of this calculus. As undefined propositional connections Orlov uses Negation $(\sim a)^{31}$ and implication $(a \rightarrow b)$, which is read as " $b$ is a necessary condition for $a$ ", or (in the manner of Orlov's 1925 paper) " $a$ presupposes $b$ ".

For the truth of the underlying implication $a \rightarrow b$ Orlov demands besides the truth of the corresponding material implication $a \supset b$ "that a certain

30 Frege, by contrast, thinks it is.

31 In this paper the sign " " is used instead of Orlov's overline negation. 
connection should obtain between the senses of sentences $a$ and $b^{\prime \prime 32}$ [Orlov $1928,264]$.

Compatibility and some other connections are introduced by definition:

$$
\begin{aligned}
& a . b \stackrel{\mathrm{df}}{=} \sim(a \rightarrow \sim b) \\
& a \mid b \stackrel{\mathrm{df}}{=} \sim(a . b) \\
& a . b . c \stackrel{\mathrm{df}}{=}(a \cdot b) . c \\
& a \leftrightarrow b \stackrel{\mathrm{df}}{=}(a \rightarrow b) .(b \rightarrow a) \\
& a \vee b \stackrel{\mathrm{df}}{=} \sim a \mid \sim b
\end{aligned}
$$

Axioms: ${ }^{33}$

$$
\begin{array}{llr}
\text { (A1) } & a \rightarrow \sim \sim a & \text { B } \\
\text { (A2) } & \sim \sim a \rightarrow a & \text { B } \\
\text { (A3) } & a \rightarrow a . a & \text { B } \\
\text { (A4) } & (a \rightarrow b) \rightarrow(\sim b \rightarrow \sim a) & \text { B }+ \\
\text { (A5) } & (a \rightarrow(b \rightarrow c)) \rightarrow(b \rightarrow(a \rightarrow c)) & \text { not in B } \\
\text { (A6) } & (b \rightarrow c) \rightarrow((a \rightarrow b) \rightarrow(a \rightarrow c)) & \text { B }
\end{array}
$$

As "Axiom 7" Orlov introduces modus ponens. ${ }^{34}$

Axiom (A3) is in fact the formula $a \rightarrow \sim(a \rightarrow \sim a)$. The formula, given as (A3), is just the abbreviation, expressed with the defined junction of compatibility.

32 Orlov does not specify what kind of sense-connection he has in mind, but his illustrating example very much resembles Bolzano's deducibility relation with reference to certain variands: "For instance, the sentence 'Socrates is a man, consequently, Socrates is mortal' is true, while the sentence 'Socrates is a man, consequently, two times two equals four' is false." In fact, the same differentiation we have in Bolzano's deducibility relation: "Socrates is a man, consequently, Socrates is mortal" is a sound deducibility with respect of the variand "Socrates" and in the second of Orlov's examples there cannot be found any variand, with respect of which this sentence would be a deducibility. And Orlov's example shows that in his mind strict implication is not enough for having the needed sense-connection: 2 times 2 equals 4 is a necessary truth, which strictly is implied by every sentence. And for compatibility in Orlov holds that the sentences "Socrates is a man" and "It is false that 2 times 2 equals 4" are compatible.

${ }^{33}$ Axiom (A1) is not independent of the other axioms. The ' $\mathrm{B}$ ' and ' $\mathrm{B}+$ ' refer to validity of analogous deducibility and precise deducibility in Bolzano.

${ }^{34}$ Orlov adds as "Axiom with non-formal charakter" the detachment-rule modus ponens (A7). 
Among the theorems, proved by Orlov himself, we find:

$$
\begin{gathered}
(a \rightarrow b) .(b \rightarrow c) \rightarrow(a \rightarrow c) \\
(a \rightarrow(a \rightarrow b)) \rightarrow(a \rightarrow b) \\
(a \rightarrow \sim a) \rightarrow \sim a \\
(\sim a \rightarrow a) \rightarrow a \\
(a \rightarrow \sim b) \rightarrow(b \rightarrow \sim a)
\end{gathered}
$$

Together with (A1) and (A2) these theorems (especially (T2d)) demonstrate that in his basic system Orlov uses negation in the classical (and not in the intuitionistic) sense. This agrees well with his positive remarks about the soundness of the principle of excluded middle. As a sound expression of the principle of excluded middle Orlov offers with reference to Hilbert: ${ }^{35}$

$$
(a \rightarrow b) \rightarrow((\sim a \rightarrow b) \rightarrow b)
$$

As is now well known, the historical importance of Orlovs system lies in its being the first formally rigorous system of relevance logic in the Anderson/Belnap sense. Orlov's system is equivalent to the negation-implicationfragment $\mathrm{R}_{\sim, \rightarrow}$ of the relevant logic $\mathrm{R} .^{36}$

In Anderson/Belnap the implication-negation fragment $\mathrm{R}_{\sim \rightarrow \rightarrow}$ of the relevant logic $\mathrm{R}$ is characterized by modus ponens and the following axioms: ${ }^{37}$

$(\mathrm{AR} 2) \quad(b \rightarrow c) \rightarrow((a \rightarrow b) \rightarrow(a \rightarrow c))$

$(\mathrm{AR} 3) \quad(a \rightarrow(b \rightarrow c)) \rightarrow(b \rightarrow(a \rightarrow c))$

(AR4) $\quad a \rightarrow a$

(AR5) $\quad(a \rightarrow \sim b) \rightarrow(b \rightarrow \sim a)$

(AR6) $\quad(a \rightarrow \sim a) \rightarrow \sim a$

$(\mathrm{AR} 7) \quad \sim \sim a \rightarrow a$

It is now easy to prove the deductive equivalence of these two systems:

\footnotetext{
35 See Hilbert 1923, 153.

36 This was first proved by Došen 1990 .

37 Anderson/Belnap 1975, 142 f.
} 
(a) All theorems of $\mathrm{R}_{\sim, \rightarrow}$ are provable in Orlov's System:

System $\mathrm{R}_{\sim, \rightarrow}$ contains besides modus ponens as axioms only axioms that correspond to formulae provable in Orlov's system: $(\mathrm{AR} 1)=(\mathrm{T} 8)$, $(\mathrm{AR} 2)=(\mathrm{A} 6),(\mathrm{AR} 3)=(\mathrm{A} 5),(\mathrm{AR} 5)=(\mathrm{T} 3 \mathrm{k}),(\mathrm{AR} 6)=(\mathrm{T} 2 \mathrm{c})$ and $(\mathrm{AR} 7)=(\mathrm{A} 2) .(\mathrm{AR} 4)$ is in $\mathrm{R}_{\sim, \rightarrow}$ a dependent axiom.

(b) Conversely, all axioms of Orlov's system are provable in $\mathrm{R}_{\sim, \rightarrow}$ :

$(\mathrm{A} 2)=(\mathrm{AR} 7),(\mathrm{A} 5)=(\mathrm{AR} 3),(\mathrm{A} 6)=(\mathrm{AR} 2)$ and hence are axioms of $\mathrm{R}_{\sim, \rightarrow}$. The remaining axioms (A2), (A3) and (A4) are theorems of $\mathrm{R}_{\sim, \rightarrow}$.

\subsection{Bolzano and Orlov: some comparisons}

Since Orlov's system and $\mathrm{R}_{\sim, \rightarrow}$ are equivalent, the comparison with Bolzano extends to the latter system as well. I shall nonetheless direct my remarks mainly to Orlov in order to determine to what extent Orlov's system satisfied the expectations he had for his logic system and the role of compatibility in it. Further, I shall not consider Orlov' system from the viewpoint of the full system $\mathrm{R},{ }^{38}$ but as a system in its own right, with special logico-intuitive claims.

In comparing the two logicians, one problem arises from the fact that Bolzano's deducibility is introduced as a relation between sentences or collection of sentences, while Orlov introduces his relevant implication as a two-placed sentence-connection that can be freely iterated, leading to higher degree formulas with respect to implication, like with $a \rightarrow a . a$, which is just an abbreviation for $a \rightarrow \sim(a \rightarrow \sim a)$. One might conclude from this, that it would be appropriate merely to compare the first-degree fragment of Orlov's system with deducibility-relations that are valid according to Bolzano. But then we would compare almost nothing, since all formula in Orlov with fusion or intensional disjunction (both defined by implication) are of course higher degree implications, while classical propositional functors like conjunction or disjunction do not even occur in Orlov's system. The following comparisons will therefore include meta-theorems about Bolzano's deducibility and compatibility and (to a small extend) considerations about the possible treatment of classical connectives in Orlov's system. The last is somewhat speculative, since Orlov did not explicitly give logical principles for classical connectives. Although his system is equivalent to the implication-negation fragment of $\mathrm{R}$, we cannot conclude that he meant to extend it to a system equivalent to $\mathrm{R}$.

\footnotetext{
38 Especially the treatment of "classical" functions like conjunction and disjunction in system $\mathrm{R}$ seems to be against the intuitive aims of Orlov.
} 
The way to higher-degree Ableitbarkeit in Bolzano's system is opened by his admitting not only relations of Ableitbarkeit, but also sentences about Ableitbarkeit, and conclusions from them (§248). Like all other sentences, they have their place in relations of Ableitbarkeit, and there are then sentences about the new Ableitbarkeit etc.

If not indicated otherwise, we restrict our account by stipulating that in all meta-formulas about Bolzano's Ableitbarkeit and compatibility the same set of variands occurs. In other words, we shall leave out reference to the sets of variands $\{i, j, \ldots\}$ in writing sentences about compatibility or Ableitbarkeit. But it should be borne in mind that $A \vDash B$ stands for $A \vDash_{\{i, j, \ldots\}} B$, $\operatorname{com}(A, B)$ stands for $\operatorname{com}(A, B,\{i, j, \ldots\})$ etc.

In the present context we shall also use, whenever appropriate, $\forall i^{\prime}\left(A^{\prime} \Rightarrow\right.$ $\left.B^{\prime}\right)$ as an abbreviation of $\forall i^{\prime} \forall j^{\prime} \ldots\left(\operatorname{var}\left(A, A^{\prime},\left\{i / i^{\prime}, j / j^{\prime}, \ldots\right\}\right) \& \operatorname{Var}\left(B, B^{\prime}\right.\right.$, $\left.\left.\left\{i / i^{\prime}, j / j^{\prime}, \ldots\right\}\right) \Longrightarrow\left(\mathrm{T}\left(A^{\prime}\right) \Rightarrow \mathrm{T}\left(B^{\prime}\right)\right)\right)$.

Orlov's system has the following theorems, which are of special interest in relation to Bolzano: ${ }^{39}$

$$
\begin{aligned}
& \sim(a . \sim b) \rightarrow(a \rightarrow b) \\
& \text { not valid in Bolzano: }{ }^{40} \sim \operatorname{com}(a, \sim b) \Longrightarrow(a \rightarrow b) .
\end{aligned}
$$

$$
\begin{array}{lr}
(a \rightarrow b) \rightarrow \sim(a . \sim b) & \text { valid in Bolzano } \\
a \mid a \rightarrow \sim a & \text { valid in Bolzano } \\
a \rightarrow a . a & \text { valid in Bolzano } \\
a . b \rightarrow b . a & \text { valid in Bolzano } \\
(a . b) . c \rightarrow a .(b . c) & \text { not valid in Bolzano }
\end{array}
$$

Bolzano does not have a metatheorem for compatibility corresponding to $(\mathrm{T} 4 \mathrm{~g})$, i.e. $\operatorname{com}(\operatorname{com}(a, b), c) \Longrightarrow \operatorname{com}(a, \operatorname{com}(b, c))$ is not valid in Bolzano. This is so because of the different scopes of quantification connected with this formula, which can be expressed by $\exists i^{\prime} j^{\prime} \ldots\left(\left(\exists i^{\prime} j^{\prime} \ldots(a \wedge b)\right) \wedge c\right) \Longrightarrow$ $\exists i^{\prime} j^{\prime} \ldots\left(a \wedge \exists i^{\prime} j^{\prime} \ldots(b \wedge c)\right){ }^{41}$

\footnotetext{
${ }^{39}$ In the following the numbers for theorems from Orlov are the same as in Orlov (1928).

40 Because of the (positive) compatibility condition.

${ }^{41}$ Here $i, j, \ldots$ are chosen as variands, and the quantification is to be understood as 1-1-substitutional quantification, i.e., the same simple or complex notions have to be substituted for the same variands, and different simple or complex notions have to be substituted for different variands. It is not difficult to find a counter-model for the formula mentioned.
} 
In Orlov's system (as in R) the compatibility of sentences, since it is introduced as inferential compatibility, does not imply semantic compatibility. A crucial fact that shows this is that, in contrast to Bolzano, Orlov has $(a . b) . c \rightarrow a . b$ (a special case of the invalid $a . b \rightarrow a$ ) false in certain cases, while $(a . \sim a) . b$ can be true, although $\sim(a . \sim a)$ is a theorem of his system. According to Orlov, $(a . b) . c \rightarrow a . b$ is not the case, if between $a . b$ and $c$ (case 1 ) or between $a$ and $b$ (case 2 ) no sense connection exists. ${ }^{42}$

Another example demonstrating the difference between semantic and inferential compatibility, derives from (TB7'), according to which $\sim(A \vDash \sim A)$ for every $A$, if $\sim A$ is not a variand. With this, Bolzano's deducibility relation fulfills an important relevance condition of connex conceptions of logical entailment. Bolzano explains this with the impossibility that a collection of concepts that makes a sentence $A$ true could also make the sentence " $A$ is false" true. This should not be misinterpreted as a metatheorem, stating that in Bolzano every sentence is compatible with itself, which it would be if interpreted in Orlov's sense, where $A$. $B$ is short for $\sim(A \rightarrow \sim B)$. The Orlov-definition simply does not define compatibility in the semantic sense of Bolzano. ${ }^{43}$

The following indicates that the logico-intuitive basic principles of Orlov are not quite in full accordance with the concept of compatibility he introduces. As for "com" in Bolzano's logical Ableitbarkeit, in Orlov has the theorem $\vdash \sim(A . \sim A) .{ }^{44}$

Hence if Orlov's system is extended to the full system R, or any other system with simplification for classical conjunction, one of Orlov's fundamental intuitive logical principles is violated, namely that incompatible sentences

\footnotetext{
${ }^{42}$ Cf. Orlov 1928, $270 \mathrm{f}$.

43 There are of course systems in which inferential compatibility coincides with semantic compatibility, as in systems based on strict implication. With material implication semantic compatibility is over-determined as (classical) conjunction, in relevant systems, like $\mathrm{R}$ or E, it is under-determined, allowing, e.g., contradictions to be inferentially compatible with irrelevant sentences.

${ }^{44}$ Orlov proclaims that in the general part of his paper (which does not treat special problems in intuitionistic logic) questions about believability or provability of given premisses are not raised. Premisses have here only the status of conditional assumptions: "In such a context the assertion of single sentences is impossible" (Orlov 1928, 265). This treatment is not only typical for systems with relevant implications of the Anderson/Belnap style, but also for systems of analytic implication and generally systems of relevant deducibility. The theorem $\sim(a . \sim a)$ does not violate this conviction, because compatibility is a derived connection in Orlov, and this theorem is to be considered as an abbreviation of $a \rightarrow \sim \sim a$.
} 
cannot be the antecedents of a valid implication. For, in such a system we can obtain by substitution from the valid $\vdash A \wedge B \rightarrow A$ the formula: $\vdash A \wedge \sim A \rightarrow A$, an implication that should be invalid by Orlov's criteria.

In the full system $\mathrm{R}$ importation for conjunction is valid, whereas exportation for conjunction is not, so that we do not obtain the irrelevant $\vdash A \rightarrow(B \rightarrow A)$ and $\vdash A \rightarrow(\sim A \rightarrow A)$ from $\vdash A \wedge \sim A \rightarrow A$. In Orlov, by contrast, we have exportation and importation for compatibility, mirroring crucial features of fusion: ${ }^{45}$

$$
\begin{aligned}
& (a \rightarrow(b \rightarrow c)) \rightarrow(a . b \rightarrow c) \\
& (a . b \rightarrow c) \rightarrow(a \rightarrow(b \rightarrow c))
\end{aligned}
$$$$
\text { (Importation law) }
$$

(Exportation law)

None of these has a corresponding meta-theorem in Bolzano.

Important deductive features of Orlov's system are expressed by the following generalization of the Leibnizian theorem $(p \rightarrow r) \wedge(q \rightarrow s) \rightarrow(p \wedge q \rightarrow$ $r \wedge s)$ that expresses a feature of consistent deductive systems. This metatheorem holds not only for Orlov and Bolzano, but also for the classical systems derided by Orlov:

If a system with $n$ compatible premisses a.b.c...k.l.m... is given, then a conclusion that follows from an arbitrary combination of premisses is compatible with the remaining premisses and with such conclusions as follow from other combinations of premisses.

[Orlov 1928, 279]

It is indeed a theorem of any connex logic that all sentences following from a given set of premisses are compatible with each other. This is a typical connex demand for logical implication and entailment, advanced not only by traditional logicians like Vladislavlev and Sigwart mentioned above, but also fulfilled by Bolzano's deducibility.

The next theorem of Orlov's System is even stronger then Bolzano's corresponding meta-theorem, because here the premisses are not supposed to be true, but just compatible with each other:

$$
(a \rightarrow b) .(a \rightarrow c) \rightarrow(a \rightarrow b . c)
$$

Orlov indicates that in his system the so-called paradoxes of material implication do not occur for the implication he introduced. This includes the invalidity of the formula corresponding to simplification $a \rightarrow(b \rightarrow a)$, and the formula corresponding to addition $a \rightarrow(\sim a \rightarrow b)$. Correspondingly,

${ }^{45}$ Cf. R6 in Routley/Meyer 1982, 365. 
neither of these formulas is a valid higher level deducibility in Bolzano. However, in Bolzano simplification and addition hold for extensional conjunction and extensional disjunction: With $\operatorname{com}(A, B)$ we have $A \wedge B \vDash A,{ }^{46}$ but, nevertheless, even under this condition we do not have $A \vDash(B \vDash A)$.

This fits very well with the invalidity of exportation in Bolzano, since we don't have valid deductions analogous to (T6b) $(a . b \rightarrow c) \rightarrow(a \rightarrow(b \rightarrow c))$, if we replace Orlov-compatibility by conjunction.

So, in Bolzano we do not have the meta-theorem

$$
a \wedge b \vDash c \Longrightarrow a \vDash(b \vDash c)
$$

And we don't have

$$
\operatorname{com}(a, b) \vDash c \Longrightarrow a \vDash(b \vDash c)
$$

Both meta-theorems fail because of the entailment condition in Bolzano's Ableitbarkeit. The importation law, on the other hand, fails because of the positive compatibility-condition. In Orlov importation holds:

$$
(a \rightarrow(b \rightarrow c)) \rightarrow(a . b \vDash c)
$$

But neither of the following are meta-theorems in Bolzano

$$
\begin{aligned}
& (a \vDash(b \vDash c)) \Longrightarrow(a \wedge b \vDash c) \\
& (a \vDash(b \vDash c)) \Longrightarrow(\operatorname{com}(a, b) \vDash c)
\end{aligned}
$$

In order to regain importation and/or exportation for higher-degree Bolzano Ableitbarkeit one must revise the treatment of the positive compatibility condition and/or negative compatibility condition (or entailment-condition).

For the validity of (3) it could be assumed that

$$
\operatorname{com}(a, \operatorname{com}(b, c)) \Longrightarrow \operatorname{com}(\operatorname{com}(a, b), c))
$$

which is associativity for Bolzano-compatibility, a condition that holds for Orlov's compatibility:

$$
((a . b) . c) \rightarrow(a .(b . c))
$$

\footnotetext{
${ }^{46}$ Another remark about Bolzano's Ableitbarkeit is in order. Remember that Ableitbarkeit is a relation between sentences, not between sentence forms. Hence no question about substitution arises, and we can say that, for all compatible sentences $A, B$, it holds that $A, B \vDash A$. This Ableitbarkeit then holds just for those specific compatible sentences not for substitutions in which we replace $A$ and $B$ by other sentences.
} 
(T5g) is merely an abbreviation of $\sim(\sim(a \rightarrow \sim b) \rightarrow \sim c) \rightarrow \sim(a \rightarrow(b \rightarrow$ $\sim c)$ ), which we get by several contrapositions from a substitution in (A3), $(a \rightarrow(c \rightarrow \sim b)) \rightarrow(c \rightarrow(a \rightarrow \sim b))$. From $(\mathrm{T} 5 \mathrm{~g})$ follows ${ }^{47}$

$$
(a .(b . c)) \rightarrow((a . b) . c)
$$

There is no theorem analogous to (A3), i.e. premiss permutation, for BolzanoAbleitbarkeit. This is not so surprising since Bolzano's Ableitbarkeit is conceived as relevant entailment in the sense of $\mathrm{E}$ rather than as relevant implication in the sense of $\mathrm{R}^{48}$

With (A3) one can obtain the famous necessity-theorem $A \rightarrow((A \rightarrow$ $A) \rightarrow A$ ) of $\mathrm{R}$, which is not valid in $\mathrm{E}$, from $(A \rightarrow A) \rightarrow(A \rightarrow A)$. And as already mentioned, it is not valid for Bolzanos Ableitbarkeit. But again, it would be misguided to consider fusion in $\mathrm{E}$ as a substitute for Bolzano-compatibility, because in $\mathrm{E}$ and its sub-logics commutativity for fusion does not hold (Routley/Meyer 1982, 365), though it does for Bolzanocompatibility.

Orlov offers his compatibility connection as replacement for classical conjunction. And in fact, if in the definition of compatibility relevant implication is replaced by material implication, then what is defined is classical conjunction. Another connection between compatibility and conjunction in Orlov demonstrates the validity of

$$
a \rightarrow(b \rightarrow(a . b))
$$

Comparing compatibility with conjunction, Orlov states with direct reference to Russell, that now certain classically valid sentences (Orlov speaks of "axioms") loose their validity. [Orlov 1928, 264] For instance, following Orlov, simplification does not hold for compatibility: " $a$ follows from $a$ and $b$ " is not valid. Of course as Russell had formulated it, simplification didn't loose its validity, because it employed classical conjunction and not some sort of compatibility. In the same way, the introduction of disjunction (addition) becomes (in Orlov's eyes) invalid. " $a$ or $b$ follows from $a$ " does not hold. However the analogies Orlov draws between classical conjunction and disjunction on the one hand, and his compatibility and incompatibility of negations on the other is just a play with words and some structural formal

\footnotetext{
${ }^{47}$ It is reasonable to suppose that Orlov meant to write this formula, and that his T5h is actually a misprint

${ }^{48}$ Cf. Anderson/Belnap 1975, Anderson/Belnap/Dunn 1992.
} 
similarities. One must not forget that Orlov does not use the extensional classical conjunction and disjunction, but their intensional relevant forms, i.e., fusion and intensional disjunction [Anderson/Belnap 1975, 344]. In the fragment of $\mathrm{R}$ that he treats, not all principles hold that are generated from classically valid principles by simply replacing classical with intensional connectives. Sometimes Orlov seems unable to draw a clear line between these different kinds of connectives.

But perhaps Orlov did see the difference between his underlying logical intuition and the semantic implications of the resulting system. This might suggest an answer to the question why Orlov published nothing about logic, philosophy and related matters after his 1928 paper. He dedicated his work and writings to another, more substantial subject that connects things together and sometimes leads to interesting and even useful results, namely, chemistry, publishing several papers in this subject until 1936. After 1936 no sign of live or death of Orlov could be found. ${ }^{49}$

\section{References}

Anderson, A. R., and Belnap Jr., N. D. (1975), Entailment, vol. 1, University Press: Princeton.

Anderson, A.R., Belnap Jr., N.D., and Dunn, J.M. (1992), Entailment, vol. 2, University Press: Princeton.

Bammel, G. (1925), "The question of the logical fates of the theory of sets", Under the banner of marxism, n. 3, 7 [Г. Баммель, " $\mathrm{K}$ вопросе о логических судьбах теории множеств", Под знаменем марксизма, н. 3, 7].

Bazhanov, V.A. (2000), Scientist and the "century of wolfdogs". The fate of I. E. Orlov in logic, philosophy and science. Ulyanovsk, 30 p. [В. А. Бажанов, Ученый и "Век-волкодав". Судьба И. Е. Орлова в логике, философии, науке. Ульяновск, Изд-во УлГУ, 30 с.]

Becker, O. (1930), "Zur Logik der Modalitäten", Jahrbuch für Philosophie und Phänomenologische Forschung 11, 497-548. Partial reprint in: K. Berka, L. Kreiser (1971), Logik-Texte, Akademie-Verlag: Berlin, 152-160.

Berg, J. (1962), Bolzano's Logic, Alquist \& Wiksell: Stockholm.

Berg, J. (1981), "A Requirement for the logical basis of scientific theories implied by Bolzano's logic of variation", Acta Historiae Rerum Naturalium Necnon Technicarum Special Issue 13, 415-424.

Berg, J. (1987), Introduction to: Bolzano (1837).

${ }^{49}$ In fact it is not clear why Orlov left philosophy for chemistry (cf. Bazhanov 2000). 
Bolzano, B. (1837), Wissenschaftslehre, Seidel: Sulzbach, newly ed. by Jan Berg, in: Bernard Bolzano-Gesamtausgabe, I. Schriften: vols. 11/1 (§§1-45) (1985), $11 / 2 \quad(\S \S 46-90) \quad(1987), \quad 11 / 3 \quad(\S \S 91-120) \quad(1987), \quad 12 / 1 \quad(\S \S 121-$ 163) (1988), 12/2 (§§164-222) (1988), 12/3 (§§223-268) (1988), FrommannHolzboog: Stuttgart/Bad Cannstatt.

Buhl, G. (1961), Ableitbarkeit und Abfolge in der Wissenschaftstheorie Bolzanos (Kantstudien Ergänzungshefte 83), Köln 1961.

Church, A. (1951), "The weak theory of implication". In: A. Menne, A. Wilhelmy, H. Angsil (Hg.), Kontrolliertes Denken. Untersuchungen zum Logikkalkül und zur Logik der Einzelwissenschaften, Alber: München.

Došen, K. (1990), "The first axiomatization of a relevant logic", Konstanzer Berichte Logik \& Wissenschaftstheorie 9-90.17 S.

Dunn, J. M. (1986), "Relevance logic and entailment". In: D. Gabbay, F. Guenthner (eds.), Handbook of Philosophical Logic, vol. III: Alternatives to Classical Logic, Reidel: Dordrecht, 117-224.

Frege, G. (1879), Begriffsschrift, eine der arithmetischen nachgebildete Formelsprache des reinen Denkens, Nebert: Halle a. S.

Frege, G. (1893/1903), Grundgesetze der Arithmetik, vol. I and II, Pohle: Jena.

George, R. (1972), "Enthymematic consequence", American Philosophical Quarterly $9,113-116$.

George, R. (1981), "Review of Kambartel (1978)", History and Philosophy of Logic $2 ; 1981,176 \mathrm{f}$.

George, R. (1983), "Bolzano's consequence, relevance, and enthymemes", Journal of Philosophical Logic 12; 1983, 299-318.

George, R. (1983), "A postscript on fallacies", Journal of Philosophical Logic 12, 319-325.

George, R. (1986), "Bolzano's concept of consequence", The Journal of Philosophy $83,558-564$.

George, R. (1992), "Concepts of consequence". In: Bolzano's Wissenschaftslehre 1837-1987. International Workshop (Biblioteca di Storia della Scienza 31), Olschki: Florenz, 3-26.

Gödel, K. (1933), "Eine Interpretation des intuitionistischen Aussagenkalküls", Ergebnisse eines mathematischen Kolloquiums 4, 39-40 (Reprint in: K. Berka, L. Kreiser (1971), Logik-Texte, Akademie-Verlag: Berlin, 187-188 (reprinted with English translation in: K. Gödel, Collected Works, vol. 1: Publications 1929-1936", Oxford University Press: New York, 1986).

Herbart, J. F. (1884 ff.), Sämmtliche Werke, hrsg. von Karl Kehrbach, Leipzig.

Hilbert, D. (1923), "Die logischen Grundlagen der Mathematik", Mathematische Annalen 88, 151-165. 
Kambartel, F. (1978), Bernard Bolzanos Grundlegung der Logik, Meiner: Hamburg ${ }^{2} 1978$.

Leibniz, G. W. (1765), "Nouveaux essais sur l'entendement humain". In: Euvres philosophiques latines $\&$ françaises de feu M. de Leibnitz, ed. by E. Raspe, Amsterdam and Leipzig, 1-496.

Leśniewski, S. (1929), "Grundzüge eines neuen Systems der Grundlagen der Mathematik", Fundamenta Mathematicce 14, 1-81. (English translation in: J. van Heijenoort (ed.), From Frege to Gödel: A Source Book in Mathematical Logic, 1879-1931, Harvard University Press: Cambridge, Mass. 1967)

Lotze, R. H. (1843), Logik, Weidmann: Leipzig.

Lotze, R. H. (1874), Logik: Drei Bücher vom Denken, vom Untersuchen und vom Erkennen, Hirzel: Leipzig.

Łukasiewicz, J. (1970), "On variable functors of propositional arguments". In: J. Łukasiewicz, Selected Works. North-Holland Publ. Company: Amsterdam London, 311-324.

Massey, G. (1981), "The fallacy behind fallacies". In: P. A. French, T.E. Vehling, Jr., H.K. Wettstein (eds.), The Foundation of Analytic Philosophy, University Press: Minneapolis, 489-500.

Max, I. (1988), "Vorschläge zur logischen Explikation von Negationen mittels Funktorenvariablen", Linguistische Studien, Reihe A, Berlin, 182, 105-161.

Moh, S. K. (1950), "The deduction theorems and two new logical systems". Methodos $2,56-75$.

Orlov, I.E. (1916), "About the inductive proof", Voprosy Filosofii i Psikhologii, kn. 135, 356-388. [И. Е. Орлов, "Об индуктивном доказательстве”, Вопросы Философии и Психологии, кн. 135, 356-388.]

Orlov, I.E. (1916), "Realism in natural science and inductive method", Voprosy Filosofii i Psikhologii, kn. 131, 1-35. [И. Е. Орлов, "Реализм в естествознании и индуктивный метод", Вопросы Философии и Психологии, кн. 131, $1-35$.

Orlov, I.E. (1923), "Pure geometry and reality", Pod znamenem marksizma, N. 12, 69-74. [И.Е. Орлов, "Чистая геометрия и действительность", Под знаменем марксизма, №. 12, 69-74.]

Orlov, I.E. (1924), "Formal logic, logic of natural science and dialectics", Pod znamenem marksizma, Nr. 6-7, 69-90. [И. Е. Орлов, Логика формальная, естественно-научная и диалектика", Под знаменем марксизма, № 6-7, $69-90$.

Orlov, I.E. (1925), "Logical calculus and traditional logic", Pod znamenem marksizma, М. Nr. 4, 69-78. [И.Е. Орлов, “Логическое исчисление и традиционная логика", Под знаменем марксизма, М. № 4, 69-78.] 
Orlov, I. E. (1925b), "Logic of infinity and the theory of G. Cantor", Pod znamenem marksizma, n. 3. [И.Е. Орлов, Логика бесконечности и теория Г. Кантора. Под знаменем марксизма, № 3.]

Orlov, I. E. (1925c), Logic of natural science, Gosud. Izdat.: M[oscow].-L[eningrad]. [И. Е. Орлов, Логика естествознания, Госуд. Издат.: М.-Л.]

Orlov, I. E. (1926), "On the rationalization of mental work", Pod znamenem marksizma, 12. [И.Е. Орлов, "О рационализации умственного труда", Под знаменем марксизма, № 12.]

Orlov, I.E. (1928), "Calculus of the compatibility of sentences", Matematicheskij sbornik, М. 35, 263-286. [И. Е. Орлов, "Исчисление совместности предложений", Математический сборник, М. т. 35, 263-286.]

Popov, V.M. (1978), "Decidibility of the relevant system RA0". In: Modal'nye $i$ intensional'nye logiki, AN SSSR, Moskva. [В. М. Попов, "Разрешимость релевантной системы RA0". In: Модальные и интенсиональные логики, АН СССР, Москва.]

Routley, R., Meyer, R. K., et al. (1982), Relevant Logics and their Rivals, I: The Basic Philosophical and Semantical Theory, Ridgeview, Atascadero.

Scholz, H. (1953) "Rezension von Bar-Hillel [3]"; in: Zentralblatt für Mathematik und ihre Grenzgebiete 47; 1953; S. 12 f.

Siebel, M. (1996), Der Begriff der Ableitbarkeit bei Bolzano [Beiträge zur BolzanoForschung 7], Academia Verlag: Sankt Augustin.

Sigwart, C. (1871), Beiträge zur Lehre vom hypothetischen Urteil, Laupp: Tübingen.

Sigwart, C. (1873), Logik, Bd. I: Die Lehre vom Urteil, vom Begriff und vom Schluss, Vol. II: Die Methodenlehre, Laupp: Tübingen ${ }^{1} 1873$ and $1878,{ }^{4} 1911$.

Simons, P. (1987), "Bolzano, Tarski, and the Limits of Logic", Philosophia Naturalis $24,378-405$

Smiley, T. J. (1959), "Entailment and deducibility", Proceedings of the Aristotelian Society, n.s. 59, 233-254.

Stelzner, W. (1980), "Funktorenvariable, Funktionenvariable und nichtklassische Logik", Wissenschaftliche Zeitschrift der KMU Leipzig, Ges. u. spr. Reihe 28, 313-318.

Stelzner, W. (2001), "Zur Behandlung von Widerspruch und Relevanz in der russischen traditionellen Logik und bei C. Sigwart". In: W. Stelzner, M. Stöckler, Zwischen traditioneller und moderner Logik. Nichtklassische Ansätze, mentis: Paderborn, 239-296.

Vasil'ev, N. A. (1910), "On particular judgments, on the triangle of contraries, on the law of excluded fourth". In: Uchennye zap. Kazan. un-ta 77, kn. 10, 1-47 
[Н. А. Васильев, "О частных суждениях, о треугольнике противоположностей, о законе исключенного четвертого", Ученные зап. Казан. ун-та 77, кн. 10, 1-47].

Vasil'ev, N. A. (1912), "Imaginary (non-Aristotelian) logic". In: Zhurnal m-va nar. prosveshcheniya, Nov. ser. 40, 207-246 [Н. А. Васильев, "Воображаемая (неаристотелева) логика". In: Журнал м-ва нар. просвещения, Нов. сер. 40, 207-246].

Vasil'ev, N.A. (1912/13), "Logic and metalogic", Logos, Nr. 1-2, 53-81. [Н. А. Васильев, "Логика и металогика", Логос, № 1-2, 53-81.]

Vasil'ev, N. A. (1925), "Imaginary (non-Aristotelian) logic". In: Estratto dagli Atti dei $V$ Congresso internationale di Filosofia, 5-9 maggio, 1924, Napoli. Naples, 107-109.

Vladislavlev, M.I. (1872), Logic. Survey on inductive and deductive procedures of thinking and historical sketches: the logic of Aristotle, Scholastic dialectics, formal and inductive logic, Demakov: Sankt Petersburg, ${ }^{2} 1881$ [М. И. Владиславлев, Логика. Обозрение индуктивных и дедуктивных приемов мышления и исторические очерки: логики Аристотеля, схоластической диалектики, логики формальной и индуктивной, Демаков: СПб, $\left.{ }^{2} 1881\right]$.

Werner Stelzner

University of Bremen

FB 9/Philosophy

PO Box 330440

28334 Bremen, Germany

wstelzner@deduction.de

wstelzner@t-online.de 